\title{
Increasing homework completion and accuracy rates with parental participation for young children with Autism Spectrum Disorder
}

\author{
Lina GILIC ${ }^{1}$
}

St. John's University, USA

(Received on December 20, 2015; Accepted on April 8, 2016)

\begin{abstract}
Students with Autism Spectrum Disorder often experience difficulty completing homework assignments independently more than students without disabilities. This study examined the use of a daily report card while adding a parent teacher component on the homework completion and accuracy rates of two second grade boys diagnosed with Autism. Parental participation for graphing and reviewing the student data involved the home environment. Researchers found that the use of the daily report card for homework completion and accuracy increased student success with the added parent teacher communication component. The parent teacher intervention increased both students' homework completion by $65 \%$ and $38 \%$ respectively and accuracy rates by $123 \%$ and 30\% respectively compared, to baseline sessions. Data showed that the addition of a parent teacher graphing component can be effective with a daily report card to increase parental involvement, while also helping increase homework completion and accuracy rates in students with Autism.
\end{abstract}

Keywords: academic success, parental involvement, Autism Spectrum Disorder

El incremento de los deberes para casa y la exactitud de tarea con la participación de los padres en niños pequeños con trastorno del espectro autista

RESUMEN: Los estudiantes con trastorno del espectro autista a menudo experimentan dificultades para completar las tareas de forma independiente más que los estudiantes sin discapacidades. Este estudio examinó el uso de unas tarjetas de registro diario en las tasas de finalización de la tarea y precisión de dos niños de segundo grado con diagnóstico de autismo. Se incluyó entre las actividades de casa la representación gráfica por parte de los padres de los datos. Los investigadores encontraron que el uso de un registro diario para completar la tarea aumentó el éxito y la precisión del estudiante con el añadido de la comunicación entre padres y maestros. La intervención con padres y maestros mejoró la terminación de la tarea en los estudiantes en un 65\% y 38\% respectivamente, y tasas de precisión de $123 \%$ y $30 \%$ en comparación con las sesiones de línea de base. Los datos mostraron que la adición de un componente gráfico por parte de padres y maestros puede ser eficaz para aumentar la participación de los padres, mientras que también ayuda en las tasas de finalización de la tarea y precisión en los estudiantes con autismo.

Palabras clave: Éxito académico, participación de los padres, trastorno del espectro autista.

${ }^{1}$ Correspondence: St. John's University. School of Education, Sullivan Hall, room 402. 8000 Utopia

Parkway Queens, NY 11439. E-mail:gilicaml@stjohns.edu. 
Homework is a traditional after school component of our American school system. Homework can be defined as tasks teachers provide to students outside of school in order to strengthen self-management, while providing an opportunity to generalize skills learned during the school day (Sheridan, 2009). Research has suggested a correlation between homework completion and school achievement, yet homework is often viewed as a source of stress for many students (Axelrod, Zhe, Haugen \& Klein, 2009; Trautwein, Niggli, Schnyder, \& Ludtke, 2009).

A number of studies have been conducted to target homework completion rates and improvement of academic achievements. Many strategies rely on parent involvement whereas others focus on teaching self-management skills (Axelrod et al., 2009). The home environment is crucial to a student's educational performance and it is as important as the quality of one's teacher and curriculum. As students spend more time in their home than school, and parents have an increased ability to significantly impact their child's academics, the need to improve the home environment is critical. Cancio, West, \& Young (2004) argue that one of the most common reasons students with disabilities fail in integrated settings is due to their problems with homework completion and accuracy.

Parental involvement in a child's academic progress is a critical element in the home environment of students, and increased attention to homework completion is one way to increase a child's overall academic performance (Cancio et al., 2004). Research has proven homework to be an effective academic intervention and when parents are involved, the academic gains surpass expectations (Axelrod et al, 2009; Trautwein et al, 2009). According to Jurbergs, Palcic and Kelley (2007) parental involvement in homework and academic skill generalization is identified as a key factor for skill attainment and optimal academic performance in children diagnosed with Autism.

When evaluating components of academics, on task behavior is a crucial variable for students to complete homework (Grauvogel-Macalese \& Wallace, 2010). Students with Autism Spectrum Disorder and behavior problems will often experience difficulty completing academic tasks such as homework. Off task behavior is regularly used as a reason to explain why students fail to complete homework assignments (Axelrod et at., 2009; Graham-Day, Gardner \& Hsin, 2010). Approximately 1 out of every 66 children in the United States are diagnosed with Autism Spectrum Disorder (Centers for Disease Control and Prevention, 2014). These students often complete work slower than expected and produce poorer quality work than they are capable of completing. The daily performance of students diagnosed with Autism on homework tasks is inconsistent and falls below that of their peers (Harris, Friedlander, Saddler, Frizzelle \& Graham, 2005).

Researchers have identified Daily Behavior Report Cards as an effective intervention to monitor the daily performance of students diagnosed with Autism. Chafouleas, Riley-Tilman, Sassu, LaFrance and Patwa (2007) define a daily behavior report card (DBRC) as a widely accepted intervention used to remedy challenging behaviors and to document change in those specific behaviors. A DBRC can be referred to as a home school note, daily report card, or a good behavior note. Despite the name used, the strategy is used as a type of performance based-recording of a specific behavior (Chafouleas et al., 2007). 
Jurbergs et al. (2007) explain that school home notes are a way for parents and teachers to communicate and have been shown to promote shared responsibility of a student's academic achievement. Research has proven that school home notes are an effective strategy used for increasing children's academic performance to increase behaviors such as handing in homework, attendance, attention, and class work completion (Jurbergs et al., 2007). According to McGoey, Prodan and Condit (2007) school home notes is a popular intervention strategy that requires increased parent involvement. Although homework is a valuable tool for learning and homework problems are common among school aged children, research examining interventions for improving children's homework performance has been limited (Miller \& Kelley, 1994). Compared with the research on homework and general education students, the study of homework and students with disabilities has been limited, and the accuracy of homework completion has little focus.

According to Jurbergs et al. (2007), very few studies have examined the effectiveness of school home notes for students with Autism. There are many forms of interventions that have been used to increase astudent's homework completion and accuracy rate such as parent involvement, increasing on task behavior through daily report cards, school home notes, peer mediation, increased parent teacher communication and use of assistive technology. Each of these methods has been supported by research to be effective under certain circumstances. Yet, the effect of displaying a student's behavior in the home and school environments has not been investigated. The increased demands parents are presented with sparked the hypothesis, of whether the visual display of a student's homework completion and accuracy affect the behaviors of the student and increase parental involvement. This study investigates the effect of displaying the students' data and its connection to behavior at home in regards to homework.

\section{Participants}

\section{Method}

Students involved were two male, 7 year old participants diagnosed with Autism according to school documentation. The first participant will be referred to as student S. Student S is affable, has friends in school, but struggled academically, specifically in reading. According to his classroom teacher he rarely completed his homework assignments and had extensive latency specific to class work compared to his classmates. Student $\mathrm{S}$ had been experiencing behavioral problems in other academic areas and the classroom teacher had implemented a daily report card to monitor his behavior. The second participant will be referred to as student J. Student J was also known in his school to be affable and had many friends in several grades, but struggled academically, specifically in math and reading. Student $\mathrm{J}$ demonstrated difficulty sitting in his chair during a class period and often came to class unprepared according to his teacher. Both participants lived with their parents, siblings and attend a public school inclusion program in the suburbs of a metropolitan city. Participant approval to conduct and participate in this research was provided by the teacher, the students' parents and school. 


\section{Setting}

The setting for this experiment took place in a second grade inclusive classroom of an elementary school. The classes consisted of 24 students with three other students who had Individualized Educational Programs for Student S, and 24 students with four other students who had Individualized Educational Programs for Student J. The classroom was located on the second floor and had visual stimuli around the room that promoted teacher lessons and displayed student work. The room was spacious and the students sat in groups of 4-5 students. Student $\mathrm{S}$ sat at the bottom right corner of his class with 4 other students, and Student $\mathrm{J}$ sat at the bottom left corner of his class with 5 other students

\section{Research design}

For the purpose of this experiment, the researcher used a reversal design, which is a single subject $(\mathrm{ABAB})$ design. The reversal design allows for a reversal from baseline to intervention, and then return to baseline and re-introduction of intervention. The return to baseline and intervention will allow for analysis to determine if a functional relationship occurred between the independent and dependent variables. The interventions were introduced in a systematic order following a stable trend for each phase. The baseline was phase A, in which the dependent variable was measured without the presentation of any independent variable to observe the student as the behavior occurs in the classroom environment. The researcher implemented the first intervention phase, daily report card (DRC) and the parent teacher communication component, during phase B. A return to baseline was conducted by withdrawing the intervention to assess for any confounding variables. Following the return to baseline, the second intervention phase was implemented with the DRC and the parent teacher communication component. Researchers investigated the completion of homework and also the accuracy within the homework completion.

\section{Dependent Variables}

The dependent variables in this study included the frequency of completed homework assignments as well as the accuracy of the completed homework assignments. The experimenter specifically measured the frequency of completed homework assignments collected by the teacher each morning during homework check, as well as the signed daily report card collected by the teacher as it was due as part of homework. In order for the homework assignments to be considered accurate it must have had no more than a $10 \%$ error, meaning a correct response rate of $90 \%$ or higher. As the homework was always a review of the class work, it was expected that the students would maintain the behavior of completing assignments as observed by the classroom teacher.

\section{Independent Variables}

For the purpose of this study there are two independent variables observed by the classroom teacher. The first variable is the use of Daily Report Card (DRC) tailored to target 
specific information regarding the students' homework completion and accuracy. The second variable included a parent teacher communication component where the teacher quantified the percentage correct and percentage completed for homework daily. This percentage data was then sent home for the parent to review and graph for visual display. The data included the student's homework completion as well as accuracy. Parent graphing of data was implemented to provide parents with an active role in displaying the students' homework completion and homework accuracy. Data was collected by the teacher which was provided to parents for entry onto the line graph. Parents were requested to review this graph with the students and provide praise if the data increased as displayed on the graph. The independent variables involving the parents, specifically graphing of data and providing praise if the data increased, were completed in the home environment without any school involvement. Observations were not permitted in the home and data of the parent's behavior were not collected.

\section{Material}

The material used for this experiment included an initial participation agreement for all involved (parent/student/teacher) in the format of a collaboration form. This form operationally defined the target behavior that the experimenter would be focusing on, as well as the procedure for the study. For this experiment the target behavior involved homework completion and homework accuracy. The long term goal stated that the students would complete all assignments on time with an accuracy rate of $90 \%$ or better. The independent variable utilized Daily Report Card for homework and multiple copies were prepared for the classroom teacher to send home with the participants on a daily basis. Below is an example of the DRC used (Table 1 and Table 2):

\section{Interobserver Agreement}

During training and data collection, experimenters recorded the students' total responses using a pencil and a data form. Total number of correct responses were recorded with a plus $(+)$ and incorrect responses with a minus (-). Total percentage correct and incorrect for homework completion and homework accuracy were calculated and graphed. We trained observers by providing them with written instructions and they observed homework data collection prior to their independent observation of experimental sessions. Once they achieved $90 \%$ agreement for two consecutive sessions, they began observation of the actual experimental sessions. Interobserver agreement was collected on $32 \%$ of the sessions. Point-to-point agreement was calculated by dividing agreements by agreements plus disagreements and converting the outcome to a percentage. The mean IOA across all participants for probe and learn unit sessions was $98 \%$, with a range of $97 \%$ to $100 \%$. 
Table 1. School and home contract for Daily Report Card

DAILY REPORT CARD AGREEMENT

DATE:

STUDENT (

) TARGET BEHAVIOR(S):

TEACHER (

) TARGET BEHAVIOR(S):

PARENT (

) TARGET BEHAVIOR(S):

DATE FOR DATA COLLECTION TO START:

HOW OFTEN WILL PARENT AND TEACHER COMMUNICATE WITH THE DAILY REPORT CARD?

HOW OFTEN WILL PARENT GRAPH HW COMPLETION AND ACCURACT FROM THE DAILY REPORT CARD?

PARENT SIGNATURE:

TEACHER SIGNATURE:

\section{Procedure}

\section{Baseline}

Baseline was collected in the second grade inclusive classrooms of a public school. For both Student S and Student J, all of the observations took place in the morning period between arrival and the morning work period, which was displayed on the classroom smart board. Students were expected to present their homework to the teacher at the beginning of the first morning period. During the first five to ten minutes of the period, the experimenter would check the students' homework for completion and accuracy, and then record the results. This was an established routine for the students, as the teacher would check for homework completion each morning. The check for accuracy was added to the participants for the purpose of this experiment. Parents were reminded not to graph and not to provide praise or correction to maintain baseline conditions. 
Table 2. Daily Report Card form for teacher parent participation

Name:

DAILY REPORT CARD FOR HOMEWORK

Date:

Teacher/Class:

TONIGHT'S HOMEWORK ASSIGNMENT:

\begin{tabular}{|l|c|c|}
\hline TARGET BEHAVIORS: & YES & NO \\
\hline WRITE DOWN HOMEWORK ASSIGNMENT & & \\
\hline BRING HOMEWORK ASSIGNMENTS TO CLASS & & \\
\hline RETURN DRC SIGNED BY PARENT & & \\
\hline
\end{tabular}

\% OF HOMEWORK ASSIGNMENT COMPLETED

\% OF HOMEWORK ASSIGNMENT ACCURATE

TEACHER COMMENTS:

PARENT COMMENTS:

\section{DRC with parental involvement}

After baseline was collected, the independent variable was introduced. The DRC was presented and the students were expected to present the form to their parents daily to have them complete, sign and return in the homework folder. To includeparental participation, parents were requested to graph the percentage completed and percentage correct for all homework, as well as to review thegraph with the students. If the data for the target behaviors increased, praise was provided to the student by the parent. The student was responsible for returning the form to his classroom teacher the next day in school. This was considered part of the students' homework assignment and considered an assignment within homework. The DRC for homework was given to the student every night. Parents were provided with the quantified data to graph for visual presentation. Parents were requested to praise their child if data for homework completion or accuracy increased.

\section{Return to Baseline}

In this phase, the independent variable was removed and data was collected on the target behavior without intervention. Students $\mathrm{S}$ and $\mathrm{J}$ were held responsible for completing their homework and did not have the DRC or any parental involvement presented during this phase. 
Data was taken until a stable trend was recorded. Parents were reminded not to graph and not to provide praise or correction to maintain baseline conditions.

\section{Return to DRC with parental involvement}

After baseline was collected, the independent variable was re-introduced. The DRC was presented again and the students were expected to present the form to their parents daily to have them complete, sign and return in the homework folder. Once again, parents were requested to graph the percentage completed and percentage correct for all homework, as well as to review thegraph with the students. Parents were provided with the quantified data to graph for visual presentation. If the data for the target behaviors increased, praise was provided to the student by the parent. The student was again responsible for returning the form to his classroom teacher the next day in school.

\section{Results}

The data for the interventions and accuracy rates for student $\mathrm{S}$ and $\mathrm{J}$ are found below in Figure 1. The data was collected in the classrooms of both boys. Results are discussed for homework completion as well as homework accuracy.

\section{Student $S$}

Student S's homework completion during baseline ranged from $0 \%$ to $60 \%$ with a mean of 10 , and his accuracy rate ranged from $0 \%$ to $10 \%$ with a mean of 1.6. On the first day initial baseline was taken, Student S completed $60 \%$ of his homework assignments and received a $10 \%$ for accuracy. On the second day, Student $S$ completed $0 \%$ of his homework assignments and received a $0 \%$ for accuracy. The remaining data for baseline resulted in four sessions of $0 \%$ for completion and four sessions of $0 \%$ for accuracy.

During the first intervention DRC phase, Student S's homework completion ranged from $0 \%$ to $100 \%$ with a mean of 55 ,and accuracy rates and from $0 \%$ to $50 \%$. On the first day the intervention was implemented, Student S did not do his homework. The days following $30 \%$ of his assignments were completed, earning a mean accuracy rate of $35 \%$. Over the next five days, Student S handed in 50-100\% of his homework assignments. His accuracy increased and maintained $50 \%$. 
Student S

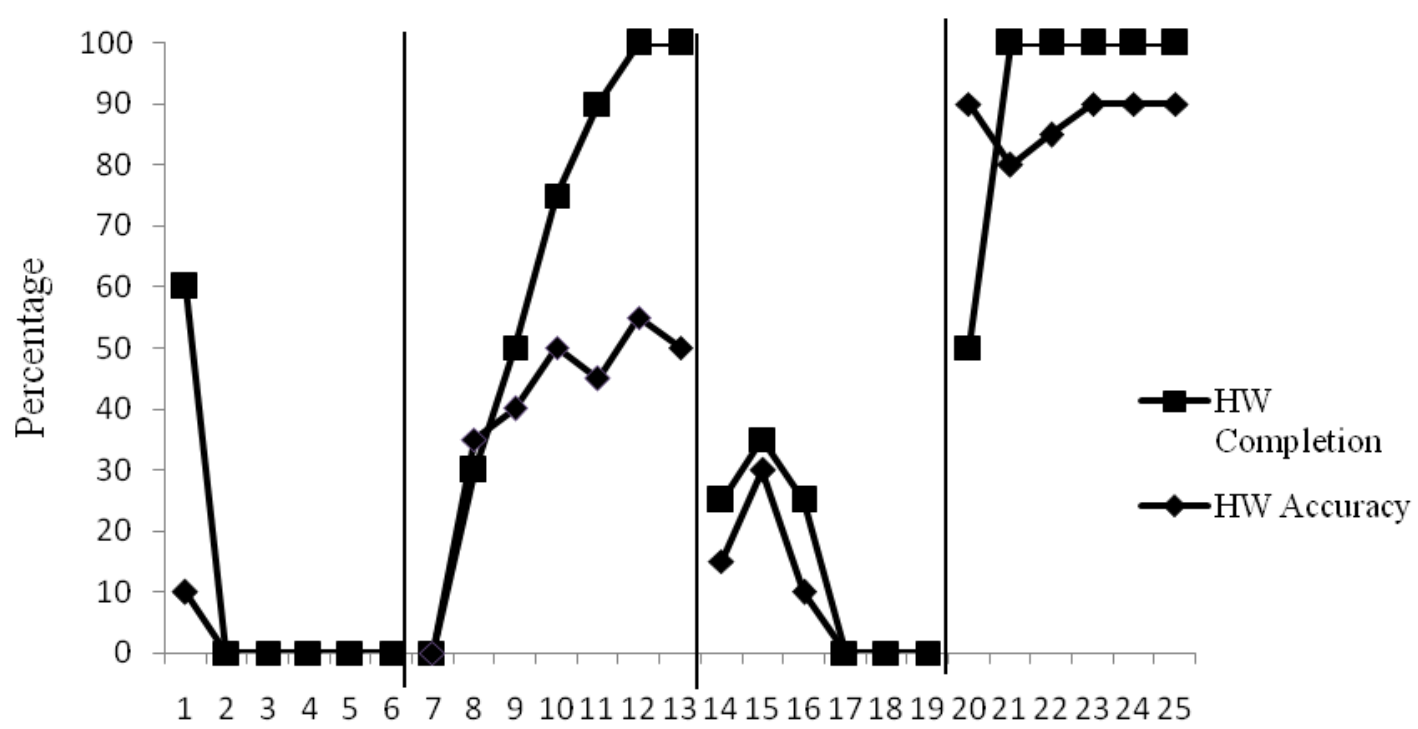

Sessions

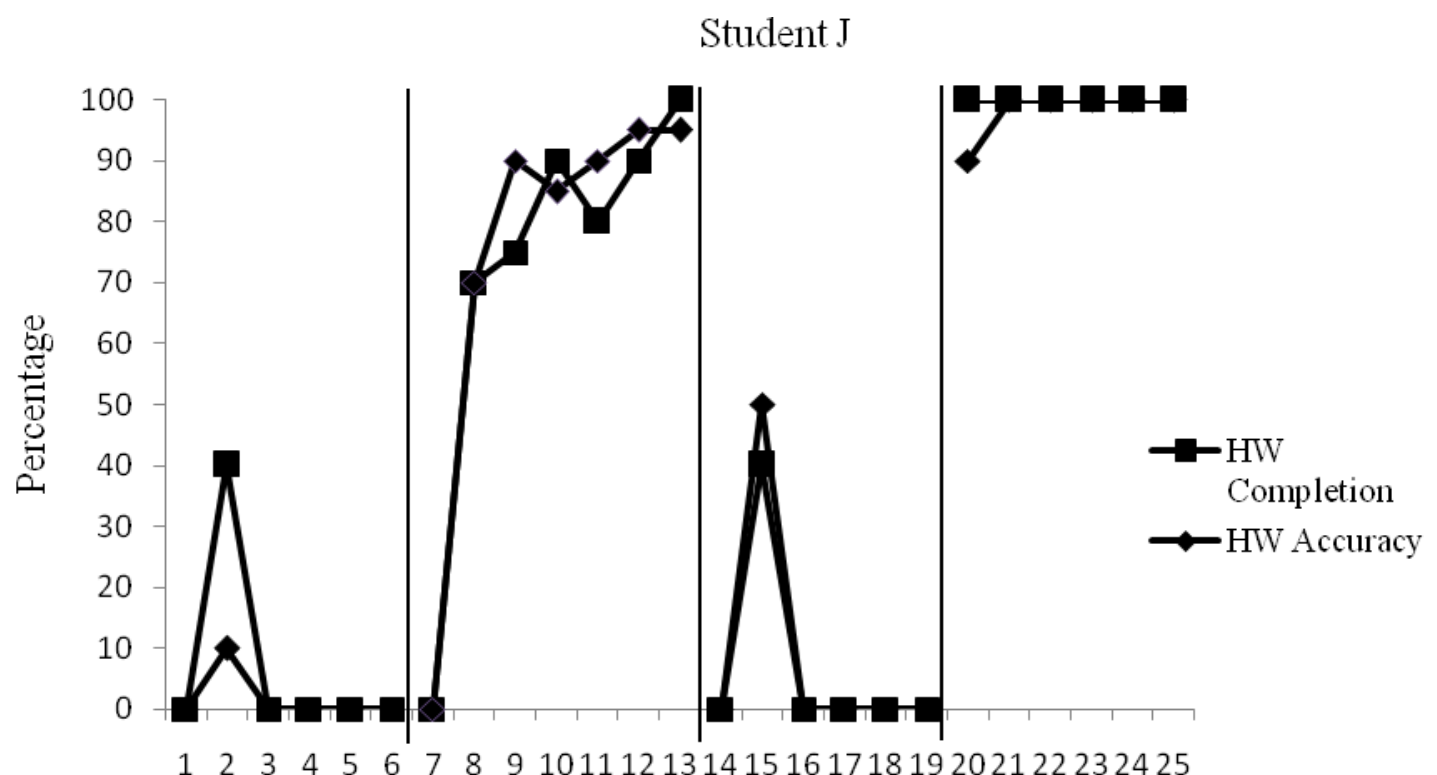

Sessions

Figure 1. Percentage correct for homework completion and home work accuracy

Student S's homework completion and accuracy rates during the return to baseline phase ranged from $0 \%$ to $35 \%$, and accuracy from $0 \%$ to 30\%. Student S completed $25 \%$ of assignments on the first day with 15\% accuracy. The next two day Student S completed 35\% and $25 \%$ of his assignments, and $30 \%$ and $10 \%$ accuracy. The next sessions Student S's completion and accuracy data resulted in $0 \%$. 
Student S's homework completion and accuracy rates during the second intervention maintained at $100 \%$, with an accuracy rate ranging from $80 \%$ to $90 \%$. Student S completed all of his assignments on the return to the parental involvement intervention and maintained the accuracy rate of $100 \%$ following the first session.

\section{Student $\boldsymbol{J}$}

Student J's homework completion during baseline ranged from $0 \%$ to $40 \%$ with a mean of 6.6 , and his accuracy rate ranged from $0 \%$ to $10 \%$ with a mean of 1.6 . On the first day initial baseline was taken, Student $\mathrm{J}$ completed $0 \%$ of his homework assignments and received a $0 \%$ for accuracy. On the second day, Student J completed $40 \%$ of his homework assignments and received a $10 \%$ for accuracy. The remained of baseline resulted in $0 \%$ for both completion and accuracy.

During the first intervention DRC phase, Student J's homework completion ranged from $0 \%$ to $100 \%$ with a mean of 72 ,and accuracy rates and from $0 \%$ to $100 \%$. On the first day the intervention was implemented, Student J did not do his homework. The days following $100 \%$ of his assignments were completed, earning a mean accuracy rate of $75 \%$. Over the next three days, Student $\mathrm{J}$ handed in $100 \%$ of his homework assignments. His accuracy increased and maintained $100 \%$.

Student J's homework completion and accuracy rates during the return to baseline phase ranged from $0 \%$ to $40 \%$, and accuracy from $0 \%$ to $50 \%$. Student J completed no assignments on the first day. The next day Student J completed $40 \%$ of his assignments, and $50 \%$ accuracy. The next sessions Student J's completion and accuracy data resulted in $0 \%$.

Student J's homework completion and accuracy rates during the second intervention maintained at $100 \%$, with an accuracy rate ranging from $90 \%$ to $100 \%$. Student J completed all of his assignments on the onset of the parental involvement intervention and maintained the accuracy rate of $100 \%$ following the first session.

\section{Discussion}

The purpose of this study was to increase homework completion and accuracy rates in two second grade students with Autism. This study confirmed the hypothesis that the use of a daily report card for homework between a student's parent and teacher with an additional direct parent teacher communication can increase homework completion and accuracy rates in students with Autism. To include parental participation, parents were requested to graph the percentage completed and percentage correct for all homework, as well as to review that graph with the students. Parental participation was presented in the home environment and without the observation or participation of the classroom teacher. Access to the home environment was not provided to assess for interobserver agreement, and as such it is not conclusive as to the effect of the parental participation and attention on the student's homework behavior.

Both students struggled with completing homework assignments and those assignments that they completed were often inaccurate. As the homework was always a review of the class work students were presented with, it was expected that the students would maintain the behavior of completing assignments as done in the classroom. The DRC was effective in increasing both Student S and Student J's homework completion and accuracy rates but questions if it would be as effective as the DRC with the parent teacher communication (C) Psy, Soc, \& Educ, 2016, Vol. 8(2) 
component. There was a significant increase in both students' completion and accuracy rates as a result of using the DRC with the parent teacher communication component used simultaneously. The DRC with the parent teacher communication component demonstrated stronger results with both boys in terms of homework completion and accuracy. Both student's responded well to the additional attention they received from parents and both student's met the expectation of achieving of $90 \%$ or better in increase in homework completion and accuracy rates. Student J was able to achieve $100 \%$ completion of all assignments with $98.6 \%$ accuracy. The parental participation of graphing homework data as well as providing praise was neither directly observed nor was parent data available. Consideration for this independent variable was found to benefit involving parents for home-school collaboration. The effect of parent participation on the student's homework completion would need further investigation.

\section{Strengths}

The implementation for this study was easy once all the materials were created. Materials can be created using several computer programs and the experimenter can tailor the DRC to include pertinent information necessary for the specific student. The study focused on two critical homework components necessary for student academic success, homework completion and accuracy. It examined two young students with Autism in the second grade inclusive environment and results demonstrated that the intervention was effective for increasing student homework accuracy behavior. Additionally, parental involvement was successful and both parents expressed wanting to know more about the class work the student were completing. Research demonstrated the benefit of parental involvement and this study was successful to implement parental involvement without disrupting the family dynamic or causing confounding variables to interfere with the experimental procedure. Both teachers and parents reported little time needed for their participation and they would be willing to implement the procedure again.

\section{Weaknesses}

The study lacked the comparison of Student S's and Student J's homework completion and accuracy behavior with their class work completion and accuracy behavior. Additionally, duration for homework and class work completion could have provided additional information for analysis. During baseline conditions, the experimenter cannot be certain whether or not parents were involved in the student's homework as home environment was void of any school personnel. Additionally, the parental participation of graphing the homework data as well as providing praise would need to be observed for data reliability and treatment integrity. It is possible that this variable may have had an impact on the data. Student absences were not an issue during the study; however the teacher was experiencing medical complication and was absent once a week for the 5 weeks of the study. The home life of students could have potentially impacted homework completion and accuracy rates as the experimenter could not account for the home environment. 


\section{Implications for Practice and Further Research}

Suggestions forfurther research would involve extending the study to other inclusive and self-contained classrooms and younger grades, as well as to collect duration data as a variable to track the time needed to complete the homework. If students master homework completion in younger grades this will allow for more continued academic success as a student completes grade levels.As duration was not assessed with this current study, the experimenter would suggest collecting data to determine the mean duration time needed to complete homework during baseline compared to the mean duration time needed to complete homework during intervention. Would the duration for homework completion during intervention increase or decrease as accuracy rates changed? Additionally, would the removal of the DRC maintain student behavior during intervention if presented only with the visual graph reviewed by parents? Increasing the number of participants to collect data on the parental participation would further the research and contribute to literature for family involvement. Difficulty arises with experimenters' access to the home environment and habituation becomes a factor but this would be a suggested addition to the research. Research findings in the literature discuss parent teacher communication and the extent of parental involvement as a critical variable for student success. Further research could investigate teacher responding to parents in order to see what practice would be the most effective. Additionally, the aspect of visual display of student data for parents and student to review together is an area needing further investigation across disciplines, age groups and continuum of services.

\section{References}

Axelrod, M. I., Zhe, E. J., Haugen, K. A., \& Klein, J. A. (2009). Self-management of on-task homework behavior: A promising strategy for adolescents with attention and behavior problems. School Psychology Review, 38(3), 325-333.

Cancio, E. J., West, R. P., \& Young, K. R. (2004). Improving mathematics homework completion and accuracy of students with EBD through self-management and parent participation. Journal of Emotional and Behavioral Disorders, 12(1), 9-22.

Centers for Disease Control and Prevention. (2014). Prevalence of autism spectrum disorder among children aged 8 years - Autism and developmental disabilities monitoring network, 11 sites, United States, 2010. MMWR Surveillance Summaries, 63, 1-21.

Retrieved from http://www.cdc.gov/mmwr/preview/mmwrhtml/ss6302a1.htm?s_cid=ss6302a1_w

Chafouleas, S.M., Riley-Tilman, T. C., Sassu, K. A., LaFrance, M. J., \& Patwa, S. S. (2007). Daily behavior report cards: An investigation of the consistency of on-task data across raters and methods. Journal of Positive Behavior Interventions, 9(1), 30-37.

Gortmaker, V., Daly, E., McCurdy, M., Persampieri, M., \& Hergenrader, M. (2007). Improving reading outcomes for children with learning disabilities: Using brief experimental analysis to develop parent -tutoring interventions. Journal of Applied Behavior Analysis, 40(2), 203-221. 
Graham-Day, K., Gardner, R., \& Hsin, Y. (2010). Increasing on-task behaviors of high school students with attention deficit hyperactivity disorder: Is it enough? Education and Treatment of Children, 33(2), 205-221.

Grauvogel-MacAleese, A. N., \& Wallace, M. D. (2010). Use of peer-mediated intervention in children with attention deficit hyperactivity disorder. Journal of Applied Behavioral Analysis, 43(3), 547-551.

Harris, K. R., Friedlander, B., Saddler, B., Frizzelle, R., \& Graham, S. (2005). Self-monitoring of attention versus self-monitoring of academic performance: Effects among students with AUTISM in the general education classroom. Journal of Special Education, 39(3), 145-156.

Hetzroni, O.E., \& Shrieber, B. (2004). Word processing as an assistive technology tool for enhancing academic outcomes of student with writing disabilities in the general classroom. Journal of Learning Disabilities, 37(2), 143-154.

Ingvarsson, E. T., \& Hanley, G. P (2006). An evaluation of computer-based programmed instruction for promoting teacher's greetings of parents by name. Journal of Applied Behavioral Analysis,39(2), 203-214.

Jurbergs, N., Palcic, J., \& Kelley, M. (2007). School-home notes with and without response cost: Increasing attention and academic performance in low-income children with attention-deficit/hyperactivity disorder. School Psychology Quarterly, 22(3), 358-379.

McGoey, K. E., Prodan, T., \& Condit, N. (2007). Examining the effects of teacher and selfevaluation of disruptive behavior via school-home notes for two young children in kindergarten. Journal of Early and Intensive Behavior Intervention, 4(1), 365-376.

Miller, D.L., \& Kelley, M. L. (1994). The use of goal setting and contingency contracting for improving children's homework performance. Journal of Applied Behavioral Analysis, 27(1), 73-84.

Myles, B., Ferguson, H., \& Hagiwara, T. (2007). Using a personal digital assistant to improve the recording of homework assignments by an adolescent with asperger syndrome. Focus on Autism and Other Developmental Disabilities, 22(2), 96-99.

National Institute of Mental Health. (2006). From NIMH research on treatment for attention deficit hyperactivity disorder (AUTISM): The multimodal treatment study. Retrieved from http://www.nimh.nih.gov/childhp/mtaqa.cfm

Riley-Tilman, T. C., Chafouleas, S. M., \& Briesch, A. M. (2007). A school practitioner's guide to using daily behavior report cards to monitor student behavior. Psychology in the Schools, 44(1), 77-88.

Rhoades, M. M., \& Kratochwill, T. R. (1998). Parent training and consultation: An analysis of a homework intervention program. School Psychology Quarterly, 13(3), 241-64.

Schumaker, J. B., Hovell, M. F., \& Sherman, J. A. (1977). An analysis of daily report cards and parent-managed privileges in the improvement of adolescents' classroom performance. Journal of Applied Behavior Analysis, 10(3), 241-264.

Sheridan, S. M. (2009). Homework interventions for children with attention and learning problems: Where is the "home" in "homework?". School Psychology Review, 38 (3), 334-337.

Simpson, C., McBride, R., Spencer, V., Lowdermilk, J., \& Lynch, S. (2009). Assistive 
technology: supporting learners in inclusive classrooms. Kappa Delta Pi Record, 45(4), 172-175.

Trautwein, U., Niggli, A., Schnyder, I., \& Ludtke, O. (2009). Between-teacher differences in homework assignments and the development of students' homework effort, homework emotions, and achievement. Journal of Educational Psychology, 101 (1), 176-189. 